\title{
NEW ASPECTS CONCERNING DYNAMICS OF RIGID SOLID BODY IN PLANE-PARALLEL MOTION SUBJECTED TO REAL CONSTRAINTS. PART TWO
}

\author{
Vladimir Dragoş TĂTARU \\ “Valahia” University, Târgovişte, Romania \\ vdtataru@gmail.com \\ Mircea Bogdan TĂTARU \\ University of Oradea, Romania \\ btataru@uoradea.ro
}

\begin{abstract}
The paper presents a numerical method of dynamic analysis of a wheel that moves along an inclined plane under the action of a motor torque. The wheel is regarded as a rigid solid body in plane motion that rolls and in the same time slides along a surface which is inclined relative to the horizontal with a certain angle of known value. Therefore, the wheel may be considered as a solid rigid body having two degrees of freedom. The movement of the wheel takes place under the action of a motor torque, active forces and link forces that are unknown. For this reason, link forces must be removed from the differential equations describing the movement of the wheel. The paper also presents a method of removing the link forces from the differential equations of motion.
\end{abstract}

KEYWORDS: dynamic study, link forces, motor wheel, rolling, sliding

\section{Introduction}

Let us consider a wheel which is leaning against an inclined plane relative to the horizontal with a known angle of inclination. The wheel is acted by a motor couple, gravity force, viscous damping force, rolling friction torque, and a sliding friction force. The inclined planealso acts a upon the wheel with a normal reaction force which of course is perpendicular on the inclined plane. The magnitude of this force is unknown. The sense of the motor torque is chosen so that the wheel climbs on the inclined plane. For a better understanding, see Figure no. 1. Without limiting the generality, it can be assumed that the wheel regarded as a free rigid solid body, describes a planeparallel motion. The movement of the wheel along the perpendicular direction on the inclined plane is blocked. Therefore, the wheel in discussion has two degrees of freedom. The dynamic behavior of the motor wheel in the case of rolling without sliding has been studied before in literature. Thus, the dynamic survey of the motor wheel in the case of pure rolling was presented by Polidor (2006), Rădoi \& Deciu (1993), Voinea, Voiculescu \& Ceauşu (1983), Staicu (1998), Vâlcovici, Bălan \& Voinea (1968). 


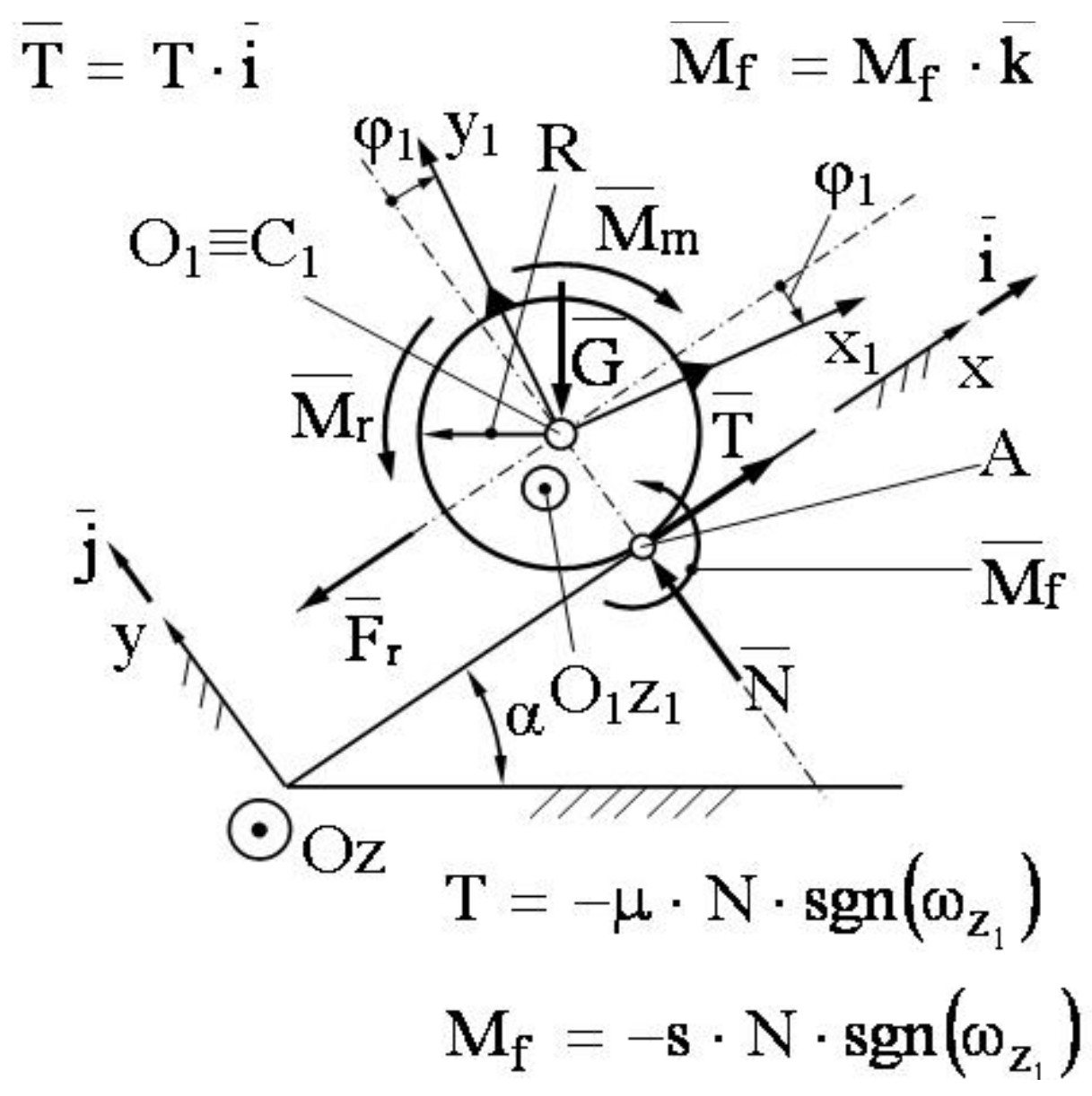

Figure no. 1: Motor wheel. Rolling in the presence of sliding

The purpose of the present paper is the numerical modeling of the dynamics of a wheel acted by a motor moment that rolls and at the same time slides along a plane surface.

2. Establishing Differential Equations Describing the Motion of the Wheel

Differential equations of motion for the rigid solid under study can be written starting from the motion equations for the rigid solid body in general motion. Particularizing these equations for the case of plan-parallel motion, the differential equations describing the motion of the motor wheel in the presence of the sliding, can be written in projections on the axis of the fixed reference system as follows:

$m_{1} \cdot \dot{v}_{O_{1} x}=-G \cdot \sin (\alpha)-c_{1 t} \cdot v_{O_{1} x}-\mu \cdot N \cdot \operatorname{sgn}\left(\omega_{z_{1}}\right)$

$$
\begin{aligned}
m_{1} \cdot \dot{v}_{O_{1} y} & =-G \cdot \cos (\alpha)-c_{1 t} \cdot v_{O_{1} y}+N \\
J_{z_{1}} \cdot \dot{\omega}_{z_{1}} & =M_{m}-c_{1 r} \cdot \omega_{z_{1}}-\mu \cdot N \cdot \operatorname{sgn}\left(\omega_{z_{1}}\right) \cdot R- \\
& \quad-s \cdot N \cdot \operatorname{sgn}\left(\omega_{z_{1}}\right) \\
\dot{x}_{O_{1}} & =v_{O_{1} x} \\
\dot{y}_{O_{1}} & =v_{O_{1} y} \\
\dot{\varphi}_{1} & =\omega_{z_{1}}
\end{aligned}
$$

where $m_{1}$ is the mass of the wheel, $G$ the gravity force, $F$ applied force parallel with the inclined plane, $\alpha$ inclined plane angle, $c_{1 t}$ viscous damping coefficient corresponding to the translational movement, $c_{1 r}$ viscous damping coefficient corresponding to the movement of rotation, $s$ rolling friction coefficient, $\mu$ sliding 
friction coefficient, $v_{O_{1} x}$ projection on $O x$ axis of $O_{1}$ point velocity, $v_{O_{1} y}$ projection on $O y$ axis of $O_{1}$ point velocity, $J_{z_{1}}$ inertia moment of the wheel relatively to $O_{1} z_{1}$ axis, $R$ radius of the wheel, $x_{O_{1}}$ and $y_{O_{1}}$ point $O_{1}$ coordinates relatively to the fixed reference frame, $\omega_{z_{1}}$ angular velocity of the wheel, $\varphi_{1}$ angle of self-rotation of the wheel. Figure no. 1 gives some more explanations. The relations (1-3) may be written together in matrix form as follows:

$$
M_{O_{1}} \cdot \dot{v}=Q_{1}+Q_{1}^{a}+Q_{1}^{c}
$$

The relations (4-6) may also be written together in matrix form as follows:

$$
\begin{aligned}
& \dot{x}=v \\
& M_{O_{1}}=\left[\begin{array}{c:c:c}
m_{1} & 0 & 0 \\
\hdashline 0 & m_{1} & 0 \\
\hdashline 0 & 0 & J_{z_{1}}
\end{array}\right] \\
& \dot{v}=\left[\begin{array}{l:l:l}
\dot{v}_{O_{1} x} & \dot{v}_{O_{1} y} & \dot{\omega}_{z_{1}}
\end{array}\right]^{T} \\
& Q_{1}=\left[\begin{array}{l:l:l}
-G \cdot \sin (\alpha) & -G \cdot \cos (\alpha) & M_{m}
\end{array}\right]^{T} \\
& Q_{1}^{a}=-C \cdot v \\
& C=\left[\begin{array}{c:c:c}
c_{1 t} & 0 & 0 \\
\hdashline 0 & c_{1 t} & 0 \\
\hdashline 0 & 0 & c_{1 r}
\end{array}\right] \\
& v=\left[\begin{array}{l:l:l}
v_{O_{1} x} & v_{O_{1} y} & \omega_{z_{1}}
\end{array}\right]^{T} \\
& Q_{1}^{c}=L_{\lambda f} \cdot \lambda
\end{aligned}
$$

$L_{\lambda f}=\left[-\mu \cdot \operatorname{sgn}\left(\omega_{z_{1}}\right): 1 !-\mu \cdot \operatorname{sgn}\left(\omega_{z_{1}}\right) \cdot R-s \cdot \operatorname{sgn}\left(\omega_{z_{1}}\right)\right]^{T}$

$$
\begin{aligned}
& \lambda=N \\
& \dot{x}=\left[\begin{array}{l:l:l}
\dot{x}_{O_{1}} & \dot{y}_{O_{1}} & \dot{\varphi}_{1}
\end{array}\right]^{T}
\end{aligned}
$$

where the exponent " $T$ "denotes the transposition matrix operation. The matrix relation (7) may be written in the following equivalent form:

$$
M_{O_{1}} \cdot \dot{v}=Q_{1}+Q_{1}^{a}+L_{\lambda f} \cdot \lambda
$$

Further on, we want to determine the motion of the wheel under the action of given forces and constraints forces. In order to do this we have to notice first that the constraint force $N$ is unknown which makes the integration of the differential equations system to be impossible. For this reason the constraint force $N$ must be removed from the differential equations system. In the next section a method of constraint force elimination will be presented.

\section{Method of Constraint Forces}

\section{Elimination}

We will multiply the matrix relation (19) to the left with the matrix $M_{O_{1}}^{-1}$ and the following result will be obtained:

$$
\dot{v}=M_{O_{1}}^{-1} \cdot Q_{1}+M_{O_{1}}^{-1} \cdot Q_{1}^{a}+M_{O_{1}}^{-1} \cdot L_{\lambda f} \cdot \lambda
$$

The matrix relation (20) will be multiplied to the left with the matrix $L_{\lambda}^{T}$ and we will obtain the following relationship:

$$
\begin{gathered}
L_{\lambda}^{T} \cdot \dot{v}=L_{\lambda}^{T} \cdot M_{Q_{1}}^{-1} \cdot Q_{1}+L_{\lambda}^{T} \cdot M_{O_{1}}^{-1} \cdot Q_{1}^{a}+L_{\lambda}^{T} \cdot M_{Q_{1}}^{-1} \cdot L_{\lambda f} \cdot \lambda \\
L_{\lambda}=\left[\begin{array}{lllll}
0 & 1 & 1 & 0 & 0
\end{array}\right]^{T}
\end{gathered}
$$

But the left member of the relation (21) is equal to zero:

$$
L_{\lambda}^{T} \cdot \dot{v}=0
$$

The relation (21) becomes:

$L_{\lambda}^{T} \cdot M_{O_{1}}^{-1} \cdot Q_{1}+L_{\lambda}^{T} \cdot M_{O_{1}}^{-1} \cdot Q_{1}^{a}+L_{\lambda}^{T} \cdot M_{O_{1}}^{-1} \cdot L_{\lambda f} \cdot \lambda=0$

The following notations will be introduced in the relation (24):

$$
\begin{aligned}
& L_{\lambda}^{T} \cdot M_{O_{1}}^{-1} \cdot L_{\lambda f}=A \\
& L_{\lambda}^{T} \cdot M_{O_{1}}^{-1} \cdot Q_{1}^{a}=\widetilde{Q}_{1}^{a} \\
& L_{\lambda}^{T} \cdot M_{O_{1}}^{-1} \cdot Q_{1}=\widetilde{Q}_{1}
\end{aligned}
$$

The matrix relation (24) becomes:

$\widetilde{Q}_{1}+\widetilde{Q}_{1}^{a}+A \cdot \lambda=0$

From the relation (28) the unknown " $\lambda$ " will be determined:

$$
\lambda=-A^{-1} \cdot\left(\widetilde{Q}_{1}+\widetilde{Q}_{1}^{a}\right)
$$


The system of differential equations describing the motion of the wheel in the presence of constraints may be written as follows:

$$
M_{O_{1}} \cdot \dot{v}=Q_{1}+Q_{1}^{a}+L_{\lambda f} \cdot\left[-A^{-1} \cdot\left(\widetilde{Q}_{1}+\widetilde{Q}_{1}^{a}\right)\right]
$$

The matrix relations (8) and (30) form together a system of six differential equations of the first order having six unknowns. These unknowns will be determined using numerical integration methods.

\section{Numerical Application}

In this section the system of differential equations established in the previous chapter will be integrated using numerical integration methods and some results will be obtained. MATLAB software was used to develop a computing program. In order to run it the following input data are required:

$$
\begin{aligned}
& m_{1}=1[\mathrm{~kg}] \\
& J_{z_{1}}=1\left[\mathrm{~kg} \cdot \mathrm{m}^{2}\right] \\
& c_{t}=1[\mathrm{~kg} / \mathrm{s}] \\
& c_{r}=1[\mathrm{~kg} \cdot \mathrm{m} / \mathrm{s}]
\end{aligned}
$$

$$
\begin{aligned}
& g=10\left[\mathrm{~m} / \mathrm{s}^{2}\right] \\
& s=0.6[\text { meters }] \\
& \mu=0.6 \\
& M_{m}=-12.5[\mathrm{~N}] \\
& \alpha=\pi / 6[\text { radians }] \\
& R=1[\text { meters }]
\end{aligned}
$$

The following initial conditions are also required:

$$
\begin{aligned}
& v_{O_{1} x}^{0}=0[\text { meters } / \mathrm{sec}] \\
& v_{O_{1} y}^{0}=0[\mathrm{~m} / \mathrm{s}] \\
& \omega_{z_{1}}^{0}=0[\text { radians } / \mathrm{s}] \\
& x_{O_{1}}^{0}=0[\text { meters }] \\
& y_{O_{1}}^{0}=R=1[\text { meters }] \\
& \varphi_{1}^{0}=0[\text { radians }]
\end{aligned}
$$

The movement of the wheel has been studied for ten seconds.

After running the program, the results presented in the figures below will be obtained (Figure no. 2 - Figure no. 4).

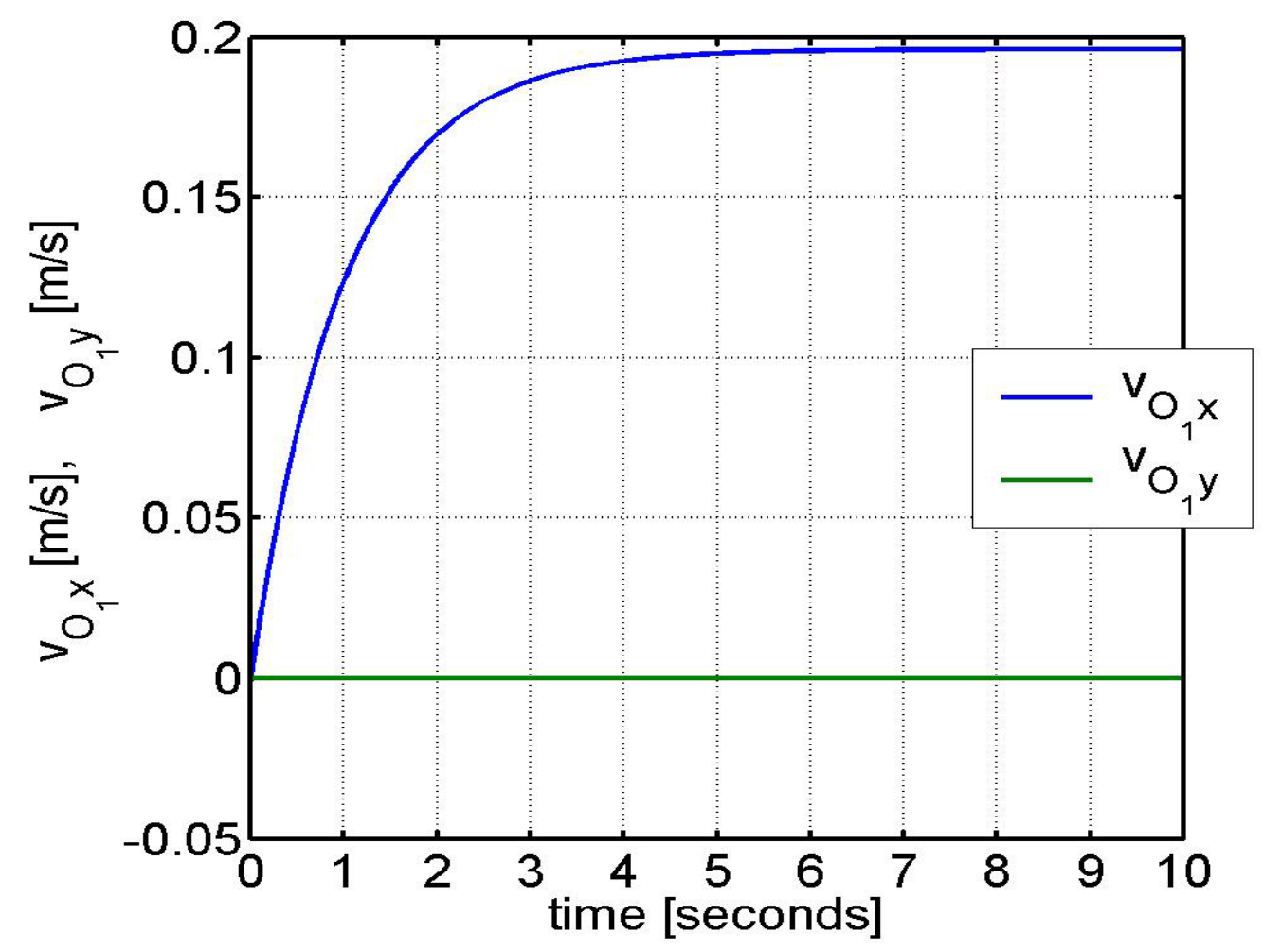

Figure no. 2: Variation of the speed components of the $O_{1}$ point versus time 


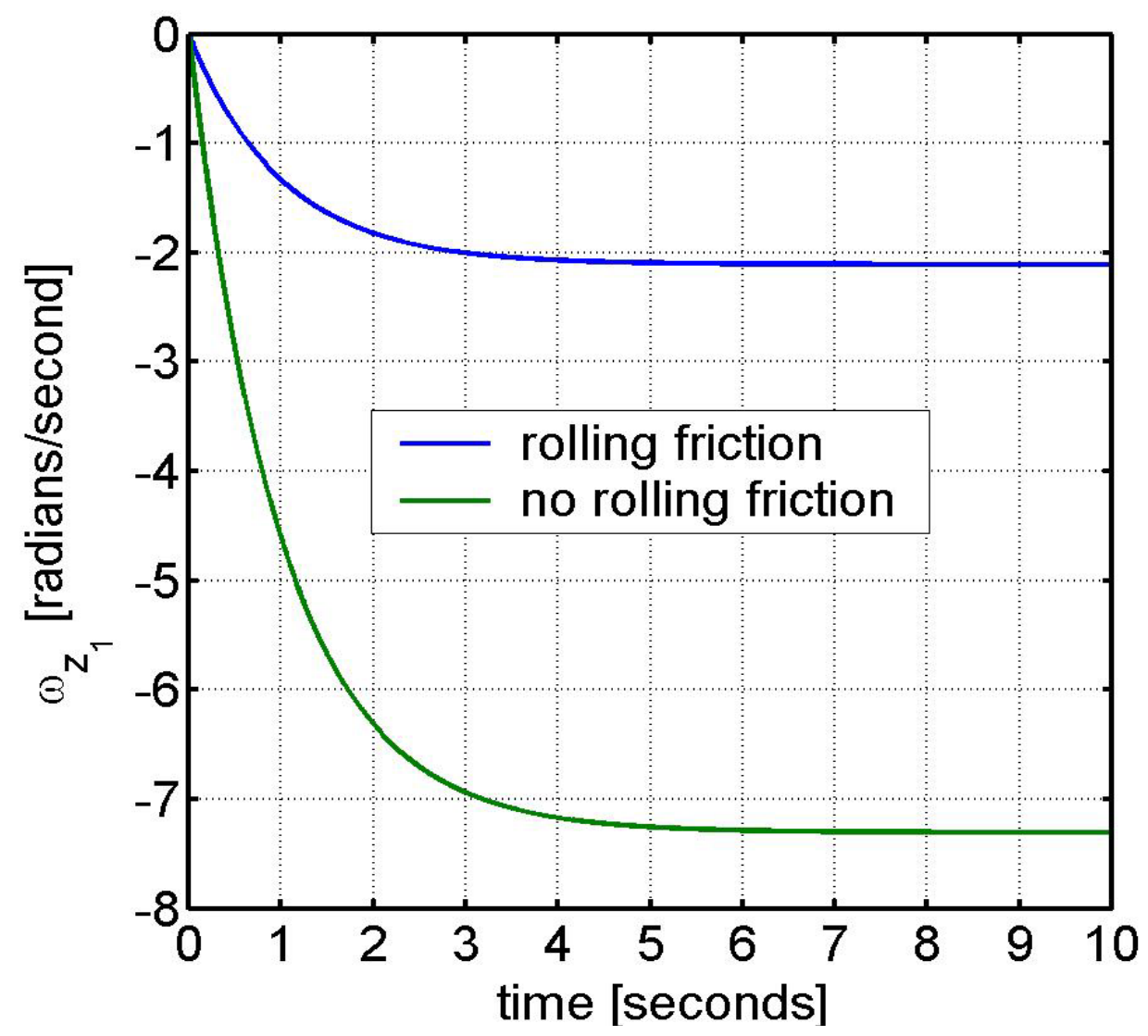

Figure no. 3: Variation of the angular speed of the wheel versus time

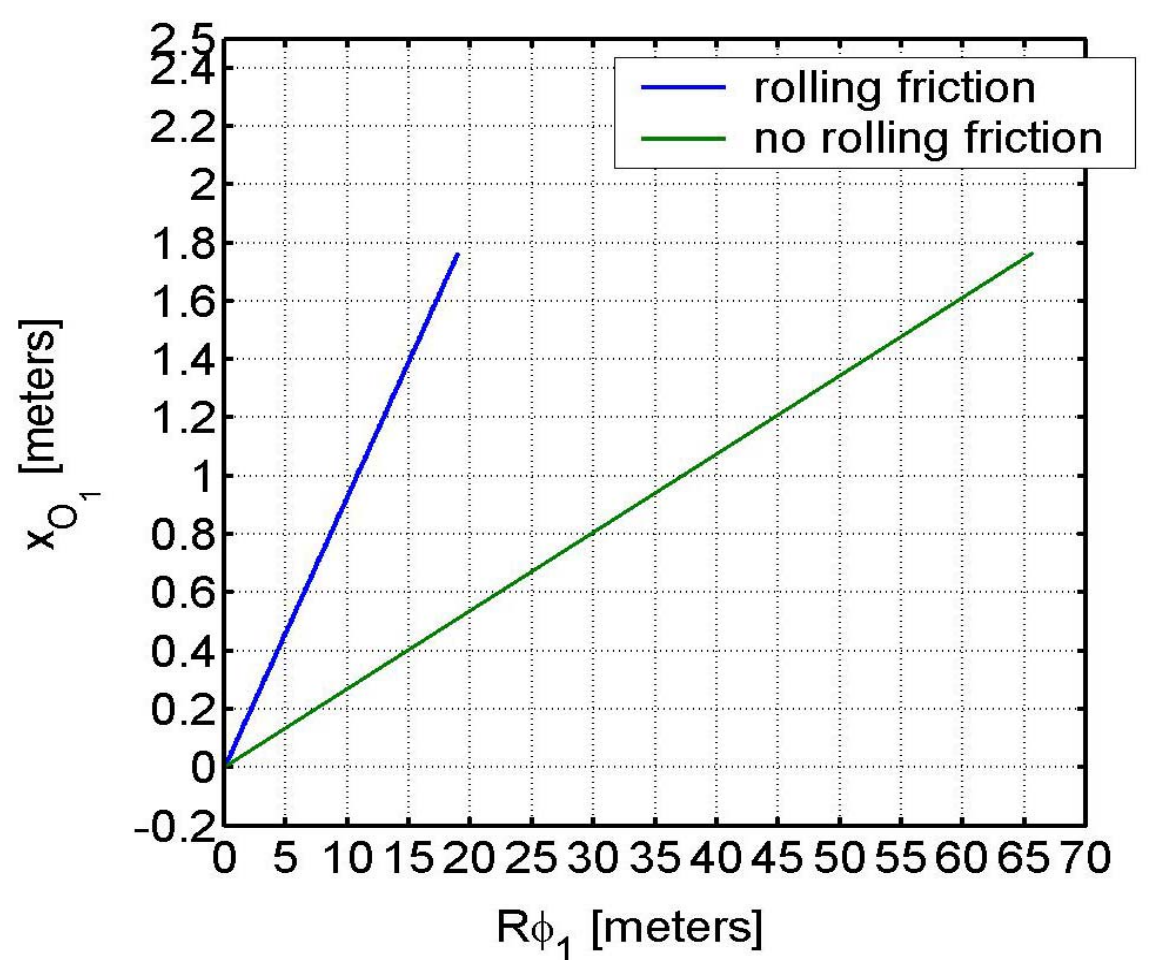

Figure no. 4: Variation of the $x_{O_{1}}$ abscissa of the $O_{1}$ point of the wheel versus $R \cdot \varphi_{1}$ product 
The movement has been studied for two distinct cases, namely: in the first case rolling friction was considered, and in the second case rolling friction was neglected. As for the speed of $O_{1}$ point, see Figure no. 2, the results in the two cases are the same and therefore just one case was shown ,namely when rolling friction was taken into account.

\section{Conclusions}

The study established the mathematical model of the dynamic analysis of the pulled wheel, which climbs on an inclined plane.
If the sliding friction coefficient " $\mu$ " is equal to zero, the sliding friction force is zero and the wheel will move to the lower side of the inclined plane. If the wheel is supported on a horizontal plane $(\alpha=0)$ then the wheel will rotate around the $O_{1} z_{1}$ axis but will not move along the $O x$ axis.

An original method of eliminating constraint forces from the differential equations system describing the motion of the solid rigid body was also presented.

\section{REFERENCES}

Polidor, B. (2006). Mecanică teoretică. Bucureşti: Editura Impuls.

Rădoi, M., \& Deciu, E. (1993). Mecanică. Bucureşti: Editura Didactică şi Pedagogică.

Staicu, Ş. (1998). Mecanică teoretică. Bucureşti: Editura Didactică şi Pedagogică.

Vâlcovici, V., Bălan, Şt., \& Voinea, R. (1968). Mecanică Teoretică. Bucureşti: Editura Tehnică.

Voinea, R., Voiculescu, D., \& Ceauşu, V. (1983). Mecanică. Bucureşti: Editura Didactică şi Pedagogică. 